\title{
MORQUIO-BRAILSFORD'S DISEASE SIMULATING THE ARTHRITIC MANIFESTATION OF RHEUMATOID DISEASE
}

\author{
BY \\ PHILIP ELLMAN \\ From the Rheumatism Unit, St. Stephen's Hospital, London
}

Rheumatoid disease in its acute or chronic form with its systemic or local manifestations may at one time or another simulate many diseases. Its local joint manifestations may resemble many specific arthritides and bony lesions with secondary joint involvement (Ellman and Ball, 1948). The purpose of this paper is to give an account of two cases of a chondro-osseous dystrophy, one of which, and possibly also the other, had at first been regarded as due to an arthritic manifestation of " rheumatoid disease". This disorder was first described by Morquio in 1929, when he reported two cases in a family of five affected children. In the same year Brailsford (1929) independently described his first case. The condition is now often referred to as the Morquio-Brailsford type of chondro-osseous dystrophy.

The primary disorder is an abnormality of development of the skeletal tissues which may vary in severity from changes apparently incompatible with life, to mild deformities of the trunk or limbs. It is characterized by multiple irregular centres of ossification in the epiphyses and diaphyses, followed later by superimposed secondary deformities and also marked muscle weakness, but even more characteristic are the constant changes in the spinethe shallow flattened vertebra with, in typical cases, the characteristic shape in the lateral view of the central tongue projecting (Figs. 6, 7, 15, 16). Of the epiphyses the hips are the most frequently affected, and in the majority of cases they show a large irregular acetabulum (Figs. 8, 10, 17), but the other epiphyses are much less often affected to any obvious degree. The reported cases have been divided by Brailsford into four separate groups.

Briefly, Group A is the most severe form, in which the spine and hip joints are mainly affected. The epiphyses of the long bones are much larger and the shafts shorter and thicker than normal. The feet and hands are also deformed, but the skull remains unaffected. With an associated muscle weakness, cases in this group run a progressively downhill course.

Group B is a variation of Group A in that the same joints are affected but the active phase seems to exhaust itself by the time puberty is reached, leaving crippling malformations.

In Group $\mathrm{C}$ the disorder is confined to the spine and hip joints, although the knees are occasionally affected.

In Group D only the vertebral column is affected.

The dwarfing which characterizes many cases is due in the main to spinal changes. The condition of the spine and hips are the two diagnostic features. Where the epiphyseal changes are marked, the differential diagnosis from dysplasia epiphysealis multiplex must be considered (Fairbank, 1947).

\section{Case Histories}

Case 1.- This case has previously been described (Ellman, 1933) and has been closely followed up for a further seventeen years. The striking feature of the case has been the patient's determination throughout to overcome his disability despite his gross skeletal deformity; through home education he has managed at intervals of time during this period to take matriculation and the degrees of B.Sc. and Ph.D., and he is now a medical student since he feels that his vocation, biochemistry, cannot adequately be mastered without a full medical training.

This patient was first seen as a boy of 15 years. He had been " healthy " till the age of 4 years, when he had an attack of measles, after which he was easily fatigued and complained of increasing stiffness, joint swellings, and inability to walk. As he became older the swellings became progressively worse.

He was an only son of parents who were first cousins. There is no family history of deformities on either side.

On examination he was found to be $4 \mathrm{ft}$. 4 in. high (normal $5 \mathrm{ft} .5 \mathrm{in}$.) and to weigh $5 \mathrm{st} .7 \frac{1}{2} \mathrm{lb}$. There was great distortion of the trunk and extremities. The trunk was very short and there was a marked kyphosis and 

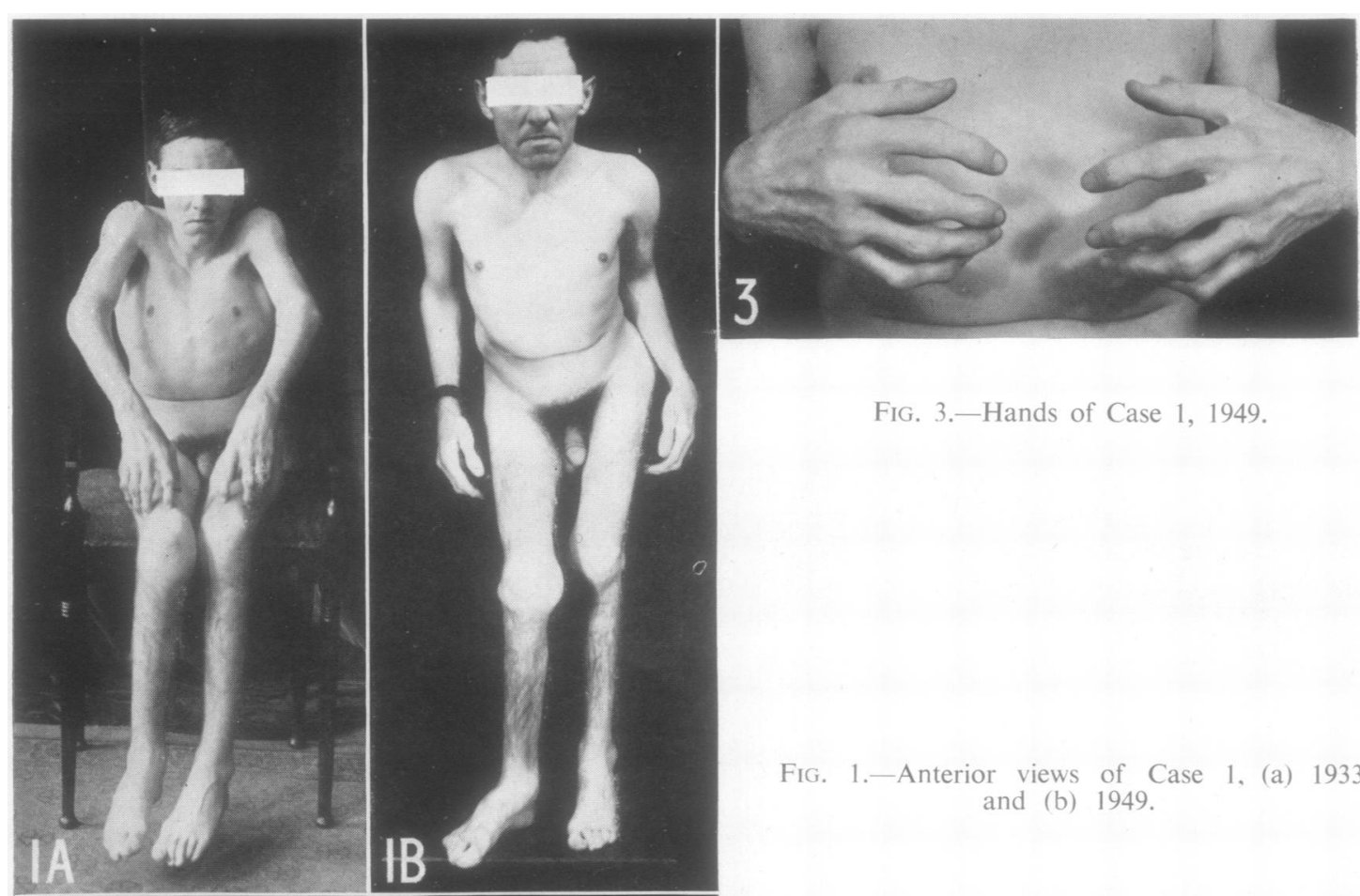

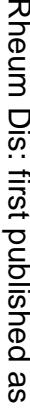

Fig. 3.-Hands of Case 1, 1949.

FIG. 1.-Anterior views of Case 1, (a) 1933 and (b) 1949.

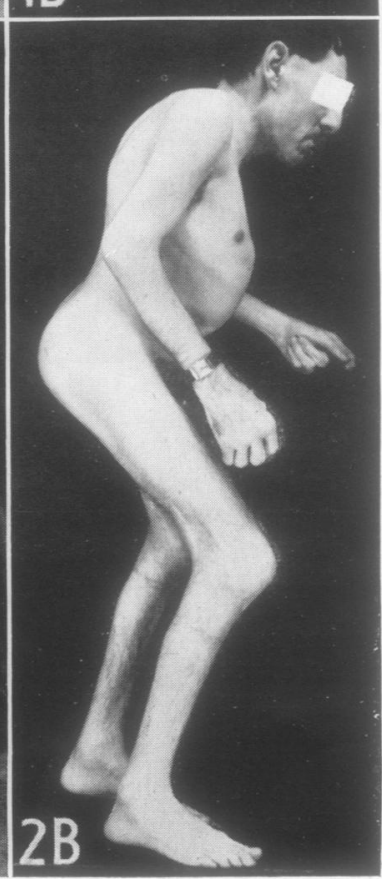

FIG. 2.-Lateral views of Case 1, (a) 1933

FIG. 2.-Lateral views of Ca
and (b) 1949.

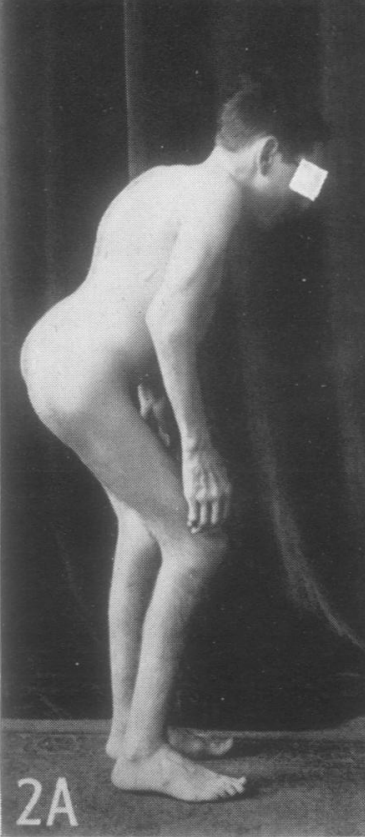




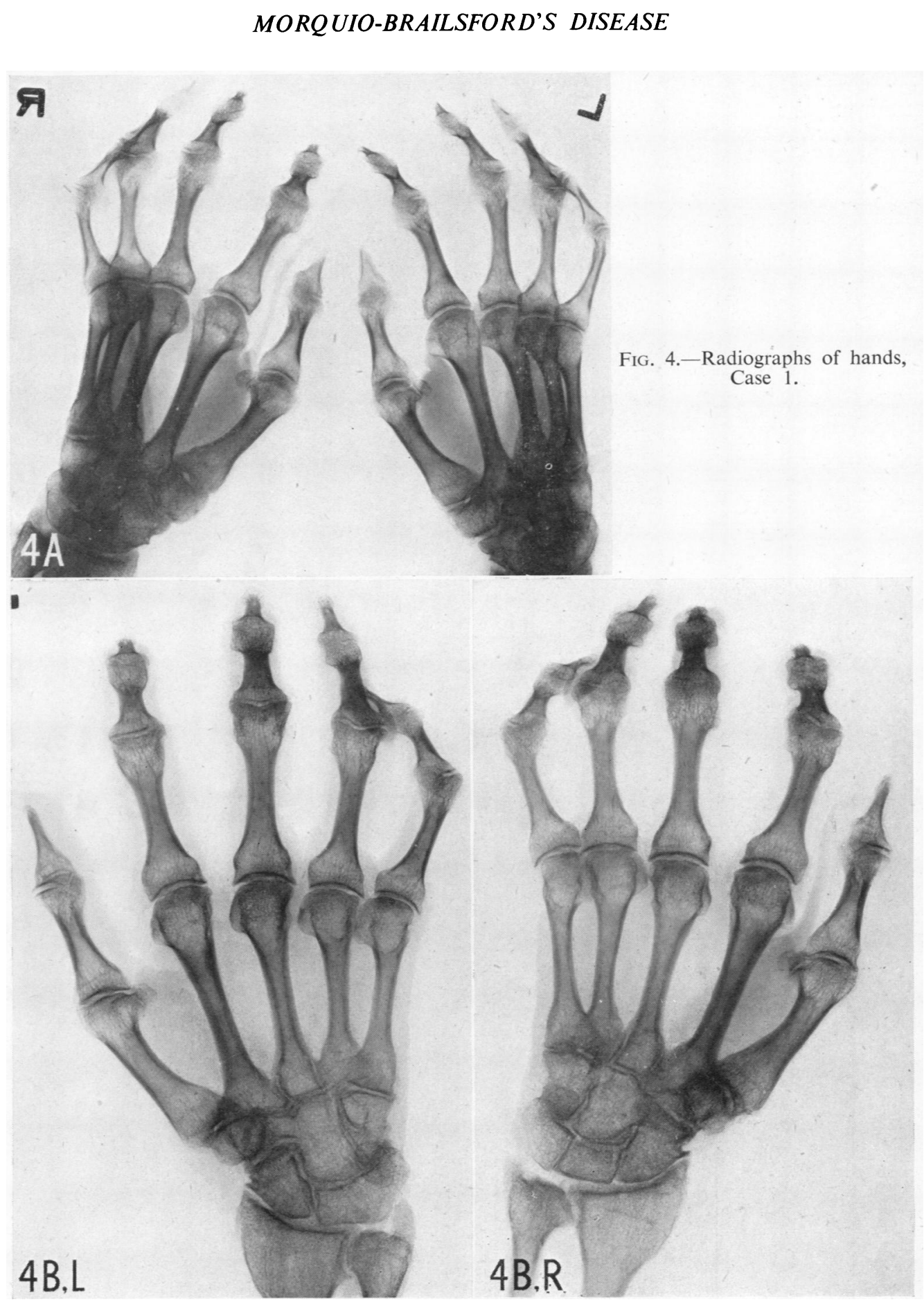




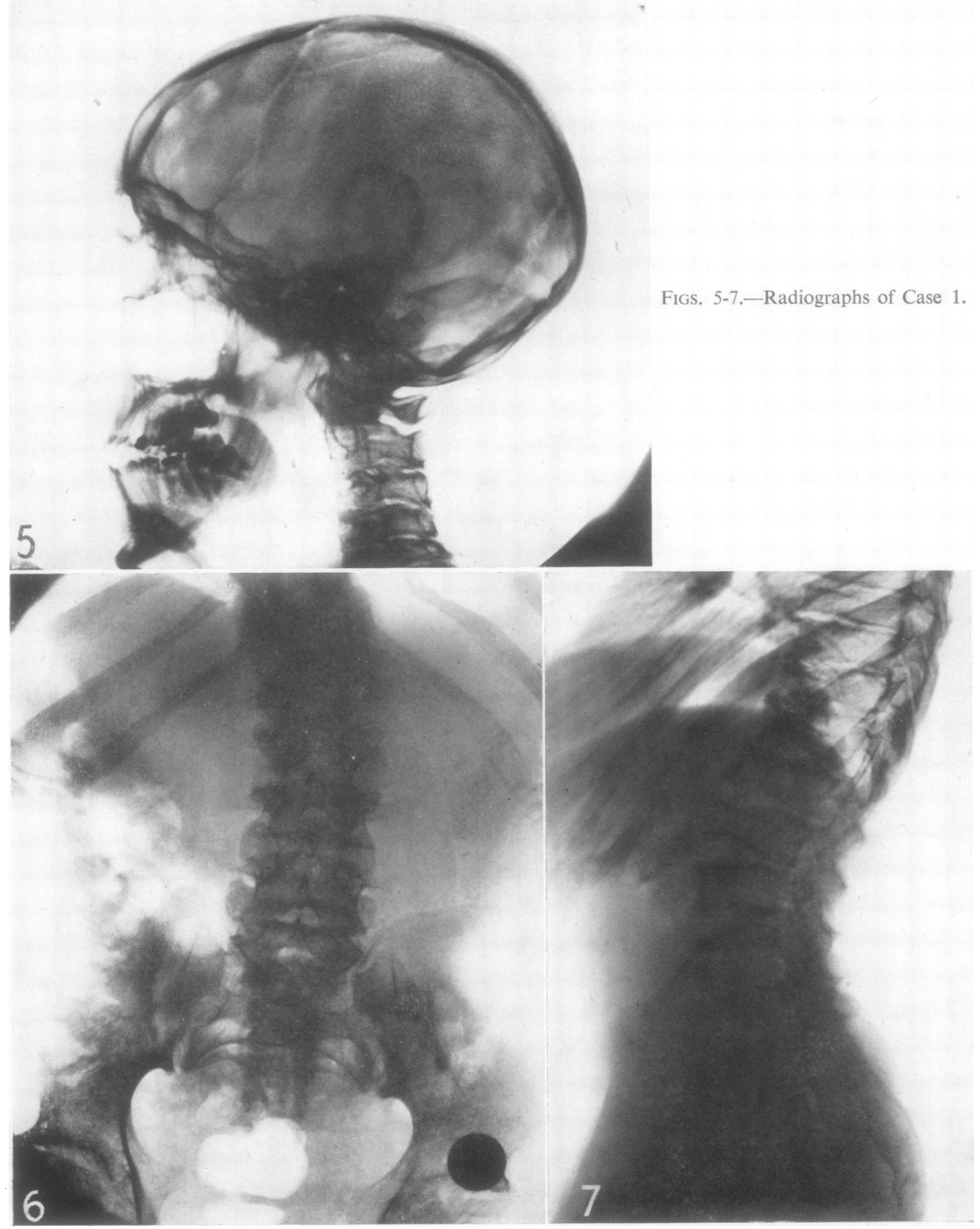




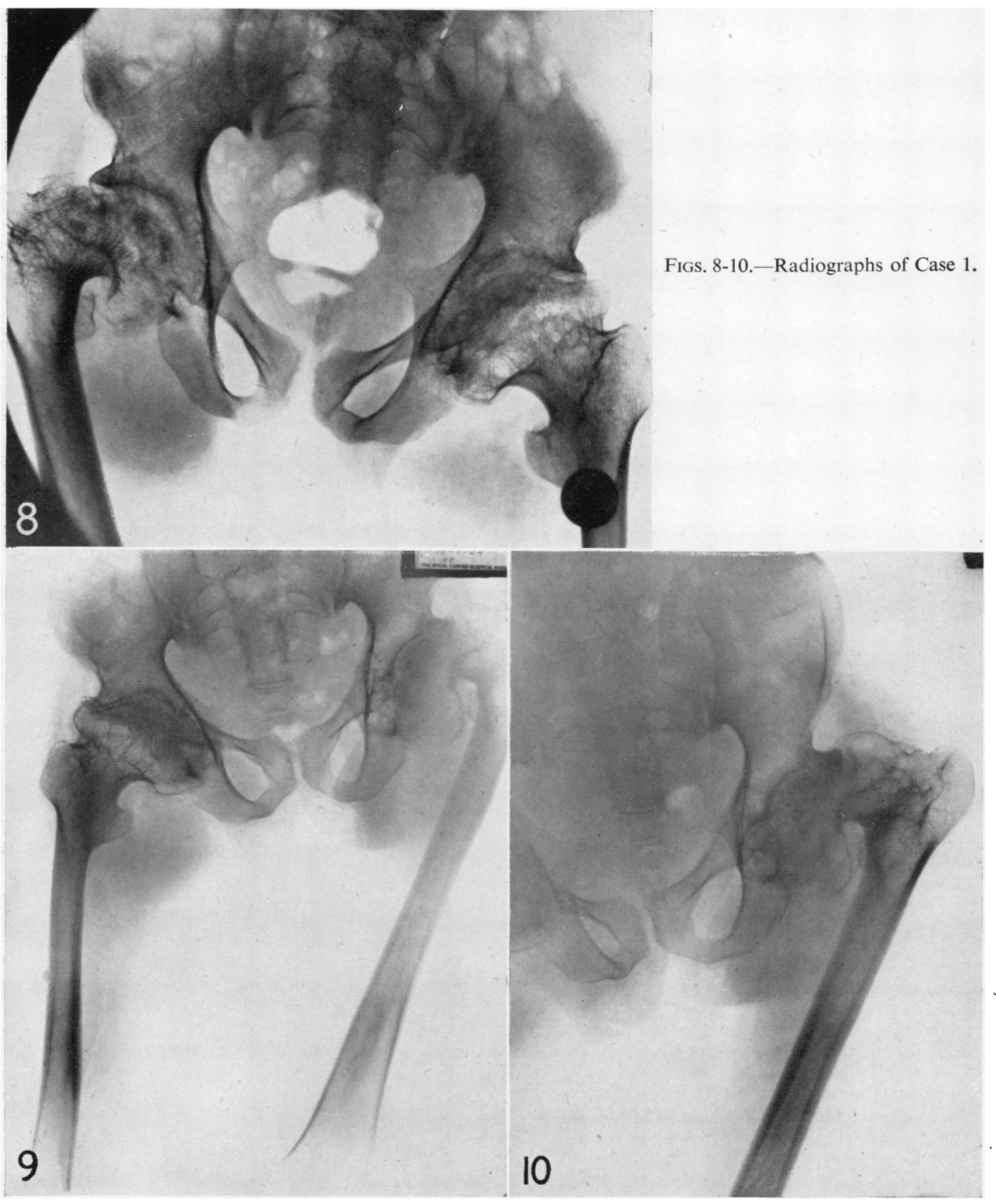

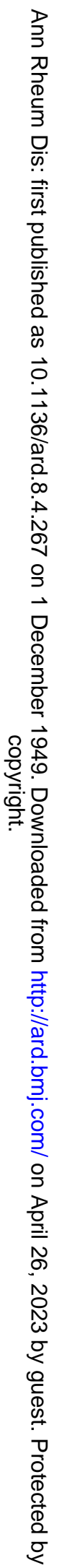




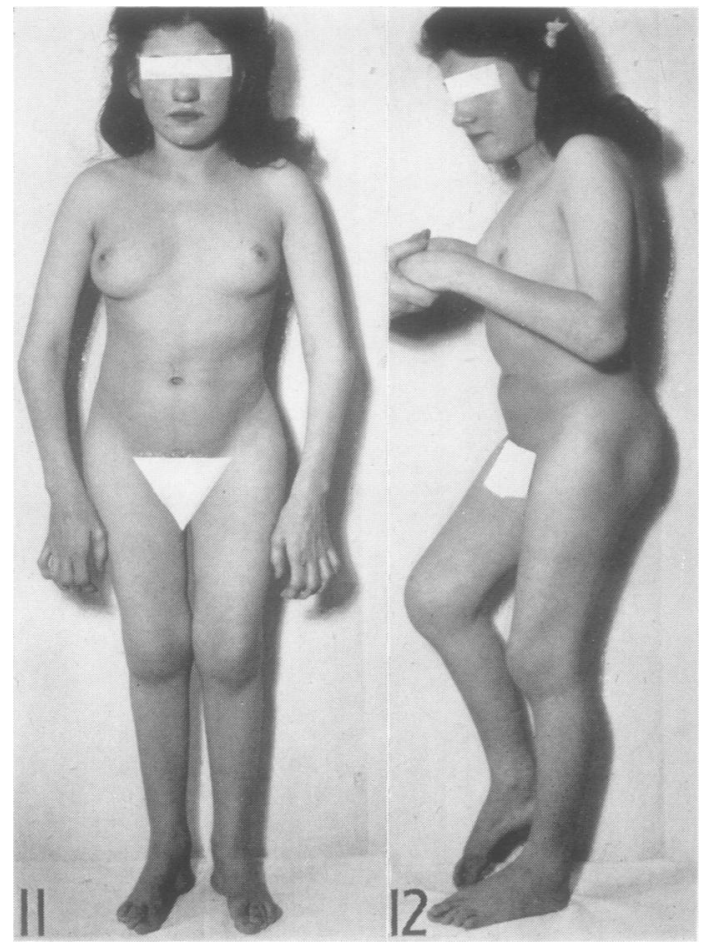

FIG. 11.-Case 2, showing disproportion.

Fig. 12.-Lateral view of Case 2, showing maximum flexion of the right hip.

pigeon-breast deformity. The normal standing position was one of crouching with the pelvis tilted forwards and to the left. The head is normal and the face is intelligent.

There was marked swelling and limitation of movement of almost all the joints, and considerable generalized muscular wasting (Figs. 1, 2, 3). There were no abnormalities in the cardiovascular, respiratory, central nervous, gastro-intestinal, or genito-urinary systems.

$X$-ray examination of the locomotor system has revealed the following abnormalities. All the bones show marked evidence of osteoporosis. The shafts of the long bones are attenuated, and the epiphyseal ends are enlarged. The heads of the femora are considerably distorted, and there is marked irregularity of the articular cartilage. There is distortion of the lower ends of the femora and upper ends of the tibia, and well marked expansion of the ends of the phalanges and metacarpal bones, with slight attenuation of the shafts of the bones. There is apparent destruction of the terminal phalangeal joints (Figs. 4-10).

Case 2.-A girl, aged 16 years, was referred to me by Dr. William Mackenzie of the W. J. Sanderson Orthopaedic Hospital School for Children, Newcastle, through the courtesy of Sir Thomas Fairbank. She was "healthy" until the age of 6 years, when painless swellings of her fingers were first noticed, which became progressively worse for two years and have since remained in the same condition. At the age of 10 years difficulty in walking was noticed, and this also became progressively worse so that for a period she was unable to walk. She lived at an Orthopaedic School for four years, and during that time learnt how to walk again. Her mental development is normal for a person of her age, and periods began at the age of 13 years. She was admitted to the Rheumatism Unit at St. Stephen's Hospital under my care (Figs. 11, 12).

The girl is the fifth child of her mother, who in the second marriage married her first cousin. Two are children of the first marriage and there are four children of the second marriage. All these are normal except the patient and one son, aged 26 years, who is only $5 \mathrm{ft}$. tall but exhibits no disproportion or radiological evidence of abnormality. The mother is also only $5 \mathrm{ft}$. tall, but exhibits no abnormality comparable to that of her daughter.

As the other members of the family were so short, the patient's small stature passed unnoticed for many years.

On examination she was found to be $4 \mathrm{ft}$. 3 in. high and to weigh 5 st. $8 \mathrm{lb}$. Her legs and arms were disproportionately long for her trunk ; her head was normal but set on a very short neck. There was marked dorsal kyphosis, and the chest had an increased antero-posterior diameter. The epiphyses of all the long bones especially the elbows and knees, were enlarged. The hands showed swellings and flexion deformities of all the inter- phalangeal joints and the lack of wasting of the interossei that occurs in the rheumatoid type of arthritis as seenco in Figs. 13 and 14. There was limitation of movement? in the elbows and the fingers, but the maximum deformity was in the hips. In these joints flexion was limited to $150^{\circ}$, abduction was 8 in. measured at the ankles, and rotation was absent. She walked with short rapid steps and a slight waddling gait. She had difficulty mounting stairs owing to the limitation of hip flexion.

There were no abnormalities in the cardiovascular, respiratory, nervous, gastro-intestinal, or genito-urinary systems.

$X$-ray examinations of the whole skeleton (Dr. Grace Batten) revealed the following abnormalities :

Spine (Figs. 15, 16).-The vertical bodies are all characteristically flat and wide and most are irregularly ossified with typical anterior moth-eaten appearances and compressions.

Pelvis and Hips. - The pelvis is broad, oblique, and flattened, with incompletely developed epiphyses for the iliac crests. There is gross deformity of the femoral heads and acetabuli, and very short femoral necks (Fig. 17 : compare Fig. 10).

Hands and Feet (Figs. 14, 18).-The bones are short with irregular broad ends. The cortices are not thickened. The carpal and tarsal bones are rather large and show cortical density. The lower ends of the radii and ulnae are irregular. Radiographs of the hands show that the joint swellings are entirely articular, without any thickening of the periarticular tissues.

Elbows. - The ends of the bones are irregular, and all 


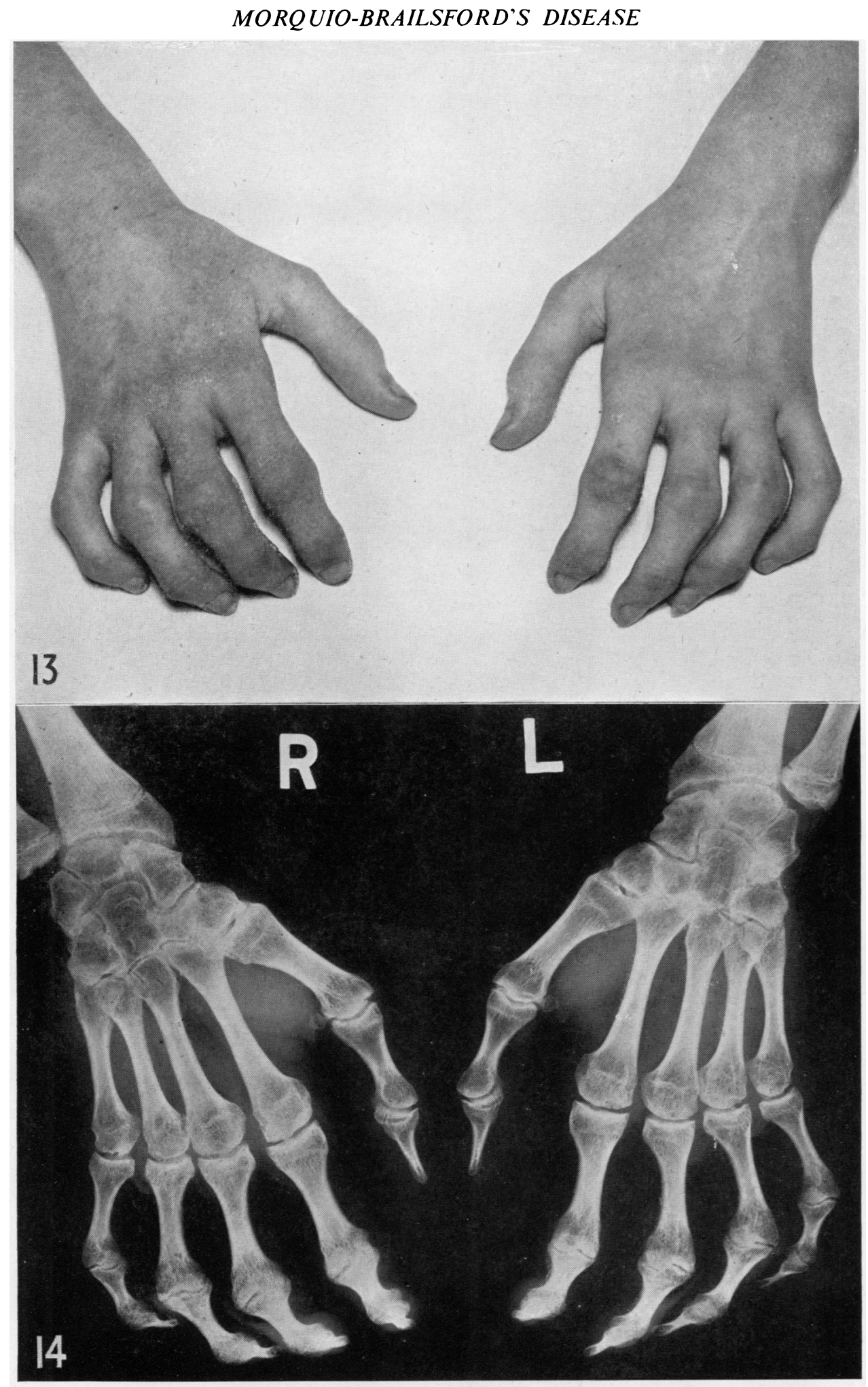

FIG. 13.-Hands of Case 2, showing similarity with rheumatoid changes. FIG. 14.-Radiograph of hands, Case 2. 


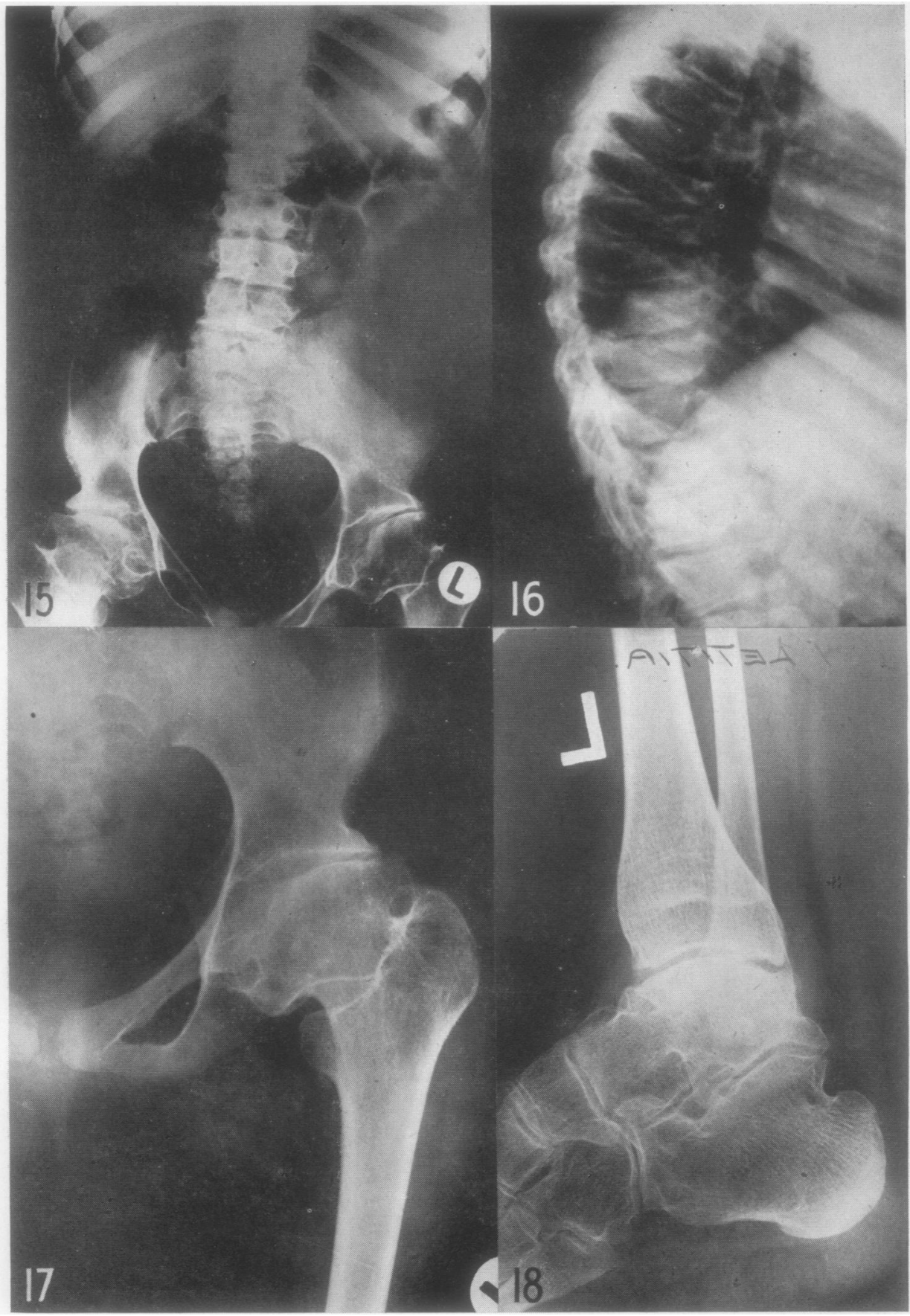

Figs. 15, 16.-Radiographs of spine, Case 2. Fig. 17.-Radiograph of pelvis and hip, Case 2. FIG. 18.-Radiograph of left ankle, Case 2. 
the epiphyses (including the internal epicondylar) are united. The long bones are all splayed out at the ends and their extremities deformed and irregular.

Changes similar to these are seen in the knees and shoulders. There is generalized osteoporosis. The skull is normal.

The similarity of physical characteristics in these cases is striking. In both cases no disorder was noticed until the patients were about 5 years old, and then the main symptoms appeared as painless swellings of the joints and difficulty in walking which must have been due at first to the primary muscle weakness associated with this condition, rather than to the secondary degenerative joint changes which have appeared since.

Table 1 gives a comparison of certain physical measurements of each patient at the age of 16 .

\section{TABLE 1}

PHYSICAL MEASUREMENTS OF CASES 1 AND 2 AT 16 YEARS

\begin{tabular}{|c|c|c|c|}
\hline & & Case 1 & Case 2 \\
\hline $\begin{array}{l}\text { Circumference of head } \\
\text { Standing height } \quad \text {.. } \\
\text { Weight } \\
\text { Length of legs } \quad \text {. } \\
\text { Length of arms } \quad \text {. } \\
\text { Chest circumference } \\
\text { Chest expansion } \quad \text {.. }\end{array}$ & \begin{tabular}{l|}
$\cdots$ \\
$\cdots$ \\
$\cdots$ \\
$\cdots$ \\
$\cdots$ \\
$\cdots$ \\
$\cdots$
\end{tabular} & $\begin{array}{ll}21 \cdot 7 & \text { in. } \\
52 & \text { in. } \\
75 \cdot 5 & \text { lb. } \\
29 & \text { in. } \\
19 & \text { in. } \\
29 & \text { in. } \\
1 \frac{1}{2} \text { in. }\end{array}$ & $\begin{array}{l}22 \text { in. } \\
51 \text { in. } \\
78 \text { lb. } \\
26 \text { in. } \\
20 \text { in. } \\
30 \frac{1}{4} \text { in. } \\
1 \frac{1}{4} \text { in. }\end{array}$ \\
\hline
\end{tabular}

The faces of both these patients appear intelligent and seem to have developed normally and in advance of the remainder of their bodies.

Table 2 gives a summary of some of the laboratory investigations in both cases.

TABLE 2

LABORATORY INVESTIGATIONS, CASES 1 AND 2

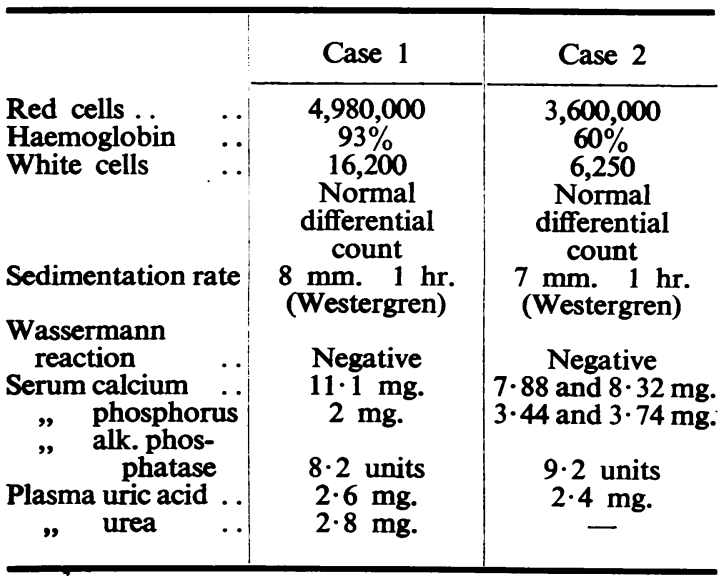

It is of interest that in the cases described by Morquio the serum calcium was low, but these figures were taken in younger patients, possibly while the disease was still active. There is no convincing reason to account for the differences in these cases.

The radiographic changes in both patients show marked similarity, as is to be seen in the reproductions ; the secondary degenerative changes in the hip joints are particularly noticeable.

The other factor which appears to be important aetiologically in this disorder is the consanguinity of the parents. In both these cases and in those described by Morquio the parents were first cousins.

\section{Differential Diagnosis}

These two cases undoubtedly correspond to the condition known as Morquio-Brailsford's disease or chondro-osseous dystrophy, and they seem to bear more similarity to Group B than to the other groups.

The condition may sometimes be confused with the rheumatoid type of arthritis, particularly when the hands are affected, as in these two cases. Fairbank, however, in a personal communication, informs me that in over sixty cases he has studied he has found that such a condition of the finger joints as exists in these two cases is exceptional ; he found it in only four cases. This does not of course mean that all the other cases had normal hands for, as he points out, thick metacarpals and rather stumpy fingers were not uncommon. One or two cases had some limitation of movement of the fingers, but did not present the striking picture seen in these two cases. Both the patients here described were thought to have rheumatoid arthritis until the generalized nature of the disease was discovered. The best means of differentiation from rheumatoid and degenerative joint disease is by $x$-ray examination, as the illustrations show. Clinically there is no pain in the development of these deformities, and there is no wasting of the interossei muscles. The swelling of the interphalangeal joints are articular rather than periarticular in origin, and involve the proximal and terminal joints. The disorder does not develop in the same manner as it does in rheumatoid or degenerative joint disease, and there is no real systemic upset. In their description, Meyer and Brenneman (1932) observed a case from the age of 10 months to $8 \frac{1}{2}$ years, and they stated that all the deformities which were apparent at the age of $8 \frac{1}{2}$ years were present when the child was first seen and had only become more obvious with the growth of the child. In Case 1 the deformities have been observed by the writer from 1933 to 1949 and there 
is astonishingly little change, taking into account the time factor.

Other remote differential diagnoses, such as spinal caries, achondroplasia or endocrinal and metabolic causes of stunted development, are readily excluded by the appropriate investigations.

\section{Comment}

This disease is chiefly characterized by changes in the spine and hips, already outlined, and to a less extent by abnormality of epiphyseal development and abnormal and extra centres of ossification which unite prematurely. There must also be some abnormality of the epiphyseal plate to prevent its further growth and to cause the diaphysis to unite with the epiphysis. These abnormalities produce the apparent joint changes described above, and compare accurately with similar cases described. One of Morquio's cases, however, showed complete absence of the carpal bones, and thus an abnormal range of movement.

The hips, taking the main weight of the body, suffer the greatest deformities, as may be seen in the radiographs. The prognosis is not improved by the possibility that secondary degenerative joint disease may be superimposed on the original damage to the epiphyses. The hips, which are the most damaged joints, suffer most. The possibility of a vitallium cup arthroplasty operation to relieve the hip-joint condition might be considered.

It is possible that, had the second case been kept in bed with both legs extended, the joint abnormalities might have been diminished before the epiphyses united, but such treatment would in all probability have had to be continued for years.

\section{Summary}

Two cases are reported of chondro-osseous dystrophy showing the typical limitation of stature, the short trunk with disproportionately long limbs, and joint abnormalities arising in the epiphyses.

There was consanguinity of the parents in both cases. This fact appears to be the most constant finding in all similar cases reported.

A possible confusion with rheumatoid disease, especially where the hands. are involved, is particularly noted.

I should like to express my indebtedness to my former house physician, Dr. L. S. Sacher, for much help in collecting the material necessary for the preparation of this paper and particularly in connexion with Case 2. I am also indebted to Dr. William Mackenzie of Newcastle and to Sir Thomas Fairbank for referring Case 2 to me, and to Dr. Grace Batten for her help with the radiographs.

\section{REFERENCES}

Brailsford, J. F. (1929). Amer. J. Surg., 7, 404.

Ellman, P. (1933). Brit. J. Child Dis., 30, 188. -, and Ball, R. E. (1948). Brit. med. J., 2, 816.

Fairbank, H. A. T. (1947). Brit. J. Surg., 34, 225.

Hardwick, C. (1938). Proc. R. Soc. Med., 31, 1167

Meyer, H. F., and Brenneman, J. (1932). Amer. J. Dis. Child., 43, 123.

Morquio, L. (1929). Arch. Med. des Enf., 32, 129.

Maladie de Morquio-Brailsford Simulant le Manifestations Arthritiques de la Maladie Rhumatismale

RÉSUMÉ

On relate deux cas de dystrophie chondro-osseuse présentant la limitation typique de la taille-le tronc court et les membres incommensurablement longsainsi que des anomalies articulaires d'origine épiphysaire. Dans les deux cas il y avait la consanguinité des parents. Il semble que ce fait est le plus constamment trouvé dans tous les cas similaires relatés. On note particulièrement la possibilité de confusion avec la' maladie rhumatismale, surtout là où les mains se trouvent atteintes. 